\title{
Photochemistry of Pentaamminethiocyanatocobalt(III) Ion
}

\author{
A. VOGLER and H. KUNKLLY \\ Fachbereich Chemie, Universität Regensburg, 84 Regensburg, Germany
}

Received December 17, 1974

Irradiation of the first ligand field band of $\mathrm{Co}\left(\mathrm{NH}_{3}\right)_{5}$ $S C N^{2+}$ in aqueous solution did not lead to any efficient photochemical reaction. Irradiation of the first $C T$ band led to a redox decomposition with formation of $\mathrm{Co}^{2+}$ and to a simultaneous linkage isomerization with formation of $\mathrm{Co}\left(\mathrm{NH}_{3}\right)_{5} \mathrm{NCS}^{2+}$. At $333 \mathrm{~nm}$ irradiating wavelength the quantum yields were 0.48 for redox reaction and 0.24 for isomerization. In the solid state $C T$ excitation led to the linkage isomerization without redox decomposition. These results are discussed with regard to the photochemistry of the complex ions $\mathrm{Co}\left(\mathrm{NH}_{3}\right)_{5} \mathrm{NO}_{2}{ }^{2+}$ and $\mathrm{Co}\left(\mathrm{NH}_{3}\right)_{5} \mathrm{NCS}^{2+}$.

\section{Introduction}

The photochemistry of aqueous $\operatorname{Co(III)~complex~}$ ammines and acidoanmines has been extensively in-

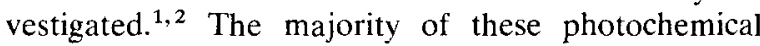
reactions is certainly initiated by $\mathrm{CT}$ excited states. However, the mechanism of the reactions which follow CT excitation is not yet completely understood. The main reactions are redox decompositions and substitutions. A remarkable exception is $\mathrm{Co}\left(\mathrm{NH}_{3}\right)_{5} \mathrm{NO}_{2}{ }^{2+}$ which also undergoes nitro-nitrito linkage isomcrization. $^{3-5}$

The complex $\mathrm{Co}\left(\mathrm{NH}_{3}\right)_{5} \mathrm{SCN}^{2+}$ offered the opportunity to study a second example of a light induced linkage isomerization. The choice of $\mathrm{Co}\left(\mathrm{NH}_{3}\right)_{5} \mathrm{SCN}^{2+}$ was initiated by an accidental observation of Buckingham, Creaser, and Sargeson, who investigated the thermal thiocyanato-isothiocyanato linkage isomerization of $\mathrm{Co}\left(\mathrm{NH}_{3}\right)_{5} \mathrm{SCN}^{2+}$. They found that this isomerization occurred also under the influence of light in the infrared spectrometer.

The comparison of the photochemistry of $\mathrm{Co}\left(\mathrm{NH}_{3}\right)_{5}$ $\mathrm{SCN}^{2+}$ and of its linkage isomer $\mathrm{Cu}\left(\mathrm{NH}_{3}\right)_{5} \mathrm{NCS}^{2+}$, which has been investigated earlier ${ }^{7-9}$, should be another interesting aspect of the present study. The homolytic bond splitting which may follow CT excitation of both complexes should generate the same radical pair $\mathrm{Co}\left(\mathrm{NH}_{3}\right)_{5}{ }^{2+}$ and $\mathrm{NCS}$. If the reactivity of this radical pair is independent of its origin CT excitation of both linkage isomers should lead to the same product distribution.

\section{Experimental}

\section{Materials}

$\left[\mathrm{Co}\left(\mathrm{NH}_{3}\right)_{5} \mathrm{NCS}\right]\left(\mathrm{ClO}_{4}\right)_{2}{ }^{10}$ and $\left[\mathrm{Co}\left(\mathrm{NH}_{3}\right)_{5} \mathrm{SCN}\right] \mathrm{Cl}_{2}{ }^{6}$ were prepared according to known procedures. The compounds wcre of good spectroscopic purity; their visible and ultraviolet absorption spectra, shown in Figure 1, and their i.r. spectra agreed well with those reported for analyzed samples. ${ }^{6}$

\section{Photolysis Procedures}

The light source used was a $100 \mathrm{~W}$ Osram highpressure mercury lamp. A Schott interference filter 333 limited the ultraviolet radiation emitted to the wavelength of the mercury line at $333 \mathrm{~nm}$. Alternatively, the Schott glass filter GG 495 transmitted light longer than $480 \mathrm{~nm}$.

The photolyses were carried out at room temperature in a $5 \mathrm{~cm}$ cylindrical spectrophotometer cell, using concentrations of complex such as to have essentially complete light absorption. The solutions were $0.01 \mathrm{M}$ in perchloric acid. An aliquot of the solution to be analyzed was kept in the dark, at the same temperature, so that any thermal reaction could be noted and allowed for. Ilowever, correction for the thermal reaction was negligible. The total amount of photolysis was limited to about $10 \%$ to avoid secondary photochemical reactions. Absorbed light intensities were determined by Ferrioxalate actinometry ${ }^{12}$ or by Reineckate actinometry ${ }^{12}$ in the visible region.

\section{Analytical Procedures \\ Cobalt (II)}

Cobaltous ion was determined by forming the blue complex ion, $\mathrm{Co}(\mathrm{NCS})_{4}{ }^{2-}$ in a water-acetone solution and measuring the absorbance $\left(\varepsilon=1.7 \times 10^{3}\right.$ at $625 \mathrm{~nm}$ ), according to a literature procedure. ${ }^{13}$

\section{Thiocyanate}

Free thiocyanate ion was determined by adding an aliquot of the irradiated (or dark) solution to a fourfold volume of a reagent consisting of $0.1 \mathrm{M}$ ferric nitrate in $0.5 \mathrm{M}$ perchloric acid, and measuring the absorbance due to the resulting ferric thiocyanate complex $\left(\varepsilon=4.3 \times 10^{3}\right.$ at $\left.450 \mathrm{~nm}\right) .^{12}$ 


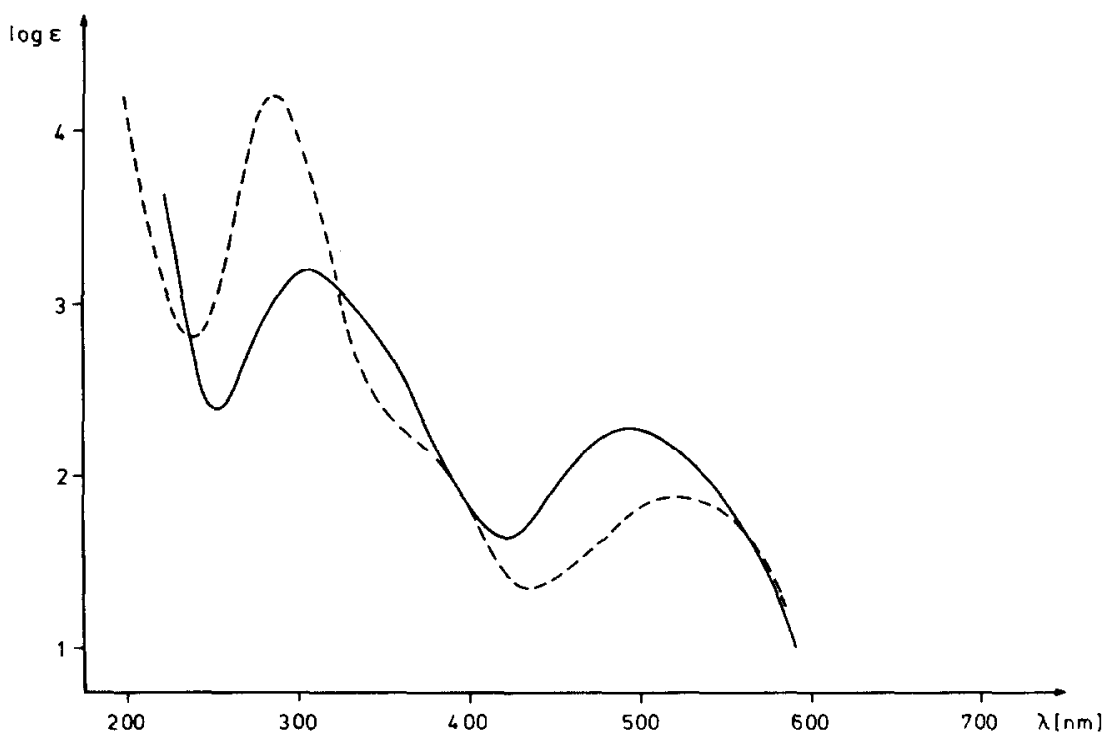

Figure 1. Electronic spectra of $\mathrm{Co}\left(\mathrm{NH}_{3}\right)_{5} \mathrm{SCN}^{2+}(----)$ and $\mathrm{Co}\left(\mathrm{NH}_{3}\right)_{5} \mathrm{NCS}^{2+}(-$ ).

\section{Measurements}

Infrared spectra were measured with a Perkin Elmer 325 IR spectrophotometer. Samples were KBr pellets. Visible and ultraviolet spectra were measured in $1 \mathrm{~cm}$ cells with a Cary 14 recording spectrophotometer and a Zeiss PMQ II spectrophotometer for measurements at selected wavelengths.

\section{Results}

The absorption spectra of $\mathrm{Co}\left(\mathrm{NH}_{3}\right)_{5} \mathrm{SCN}^{2+}$ and $\mathrm{Co}\left(\mathrm{NH}_{3}\right)_{5} \mathrm{NCS}^{2+}$ (Figure 1) exhibit their first LF maxima at $512 \mathrm{~nm}(\varepsilon=74)$ and at $498 \mathrm{~nm}(\varepsilon=$ 179). ${ }^{6}$ The intense absorption maxima at $288 \mathrm{~nm}$ $(\varepsilon=15,600)$ and at $306 \mathrm{~nm}(\varepsilon=1490)$ are assigned to $\mathrm{SCN}^{-}$and $\mathrm{NCS}^{-}$to $\mathrm{Co}$ (III) CT transitions of both complexes. Corresponding assignments have been made for the absorption bands of the two linkage isomers $\mathrm{Co}(\mathrm{CN})_{5} \mathrm{SCN}^{3-}$ and $\mathrm{Co}(\mathrm{CN})_{5} \mathrm{NCS}^{3-14}$

\section{Photolysis in Aqueous Solution}

The complex ion $\mathrm{Co}\left(\mathrm{NH}_{3}\right)_{5} \mathrm{SCN}^{2+}$ was sufficiently stable under our experimental conditions. Hence any interference by thermal reactions ${ }^{6}$ was excluded. $\mathrm{Co}\left(\mathrm{NH}_{3}\right)_{5} \mathrm{SCN}^{2+}$ did not undergo any efficient photochemical reaction if the irradiating wavelength was restricted to the region of the LF band $(\lambda>480 \mathrm{~nm})$. The quantum yield of any of the possible reactions was estimated to be smaller than $10^{-3}$.

Upon irradiation of the CT band $(333 \mathrm{~nm}$ irradiating wavelength) $\mathrm{Co}\left(\mathrm{NH}_{3}\right)_{5} \mathrm{SCN}^{2+}$ underwent a redox decomposition. $\mathrm{Co}^{2+}$ was formed with the quantum yield $\Phi=0.48$. This redox reaction was accompanied by a change of the absorption spectrum (Figure 2). It was assumed that the products of the redox decomposition have a negligible absorption down to at least $300 \mathrm{~nm}$. The extinction at longer wavelengths should then decrease according to the amount of decomposition. However, the decrease of the extinction was dependent on the wavelength and at $475 \mathrm{~nm}$ there was no change at all (Figure 2). It follows that in addition to the redox products another complex must have been formed, which had a larger extinction than the starting complex at least at $475 \mathrm{~nm}$. The most probable candidate for another photoproduct was $\mathrm{Co}\left(\mathrm{NH}_{3}\right)_{5} \mathrm{NCS}^{2+}$ which has a higher extinction than $\mathrm{Co}\left(\mathrm{NH}_{3}\right)_{5} \mathrm{SCN}^{2+}$ almost over the entire wavelength region down to $320 \mathrm{~nm}$ (Figure 1). A comparison showed that the ratio of the extinction coefficients of the isothiocyanato and thiocyanato isomers is indeed highest at $475 \mathrm{~nm}$. If the redox decomposition and linkage isomerization were the only photochemical reactions the ratio of both reaction modes can be calculated from the extinction coefficients of the two linkage isomers at $475 \mathrm{~nm}$. The calculation showed that two thirds of the photolyzed ions underwent a redox decomposition and the remaining third was transformed into its linkage isomer. The change of the extinction at any other wavelength should then satisfy the equation:

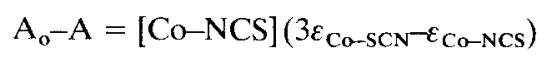

The agreement was better than $5 \%$ for all wavelengths above $400 \mathrm{~nm}$. Hence the assumption that only the redox decomposition and linkage isomerization took 


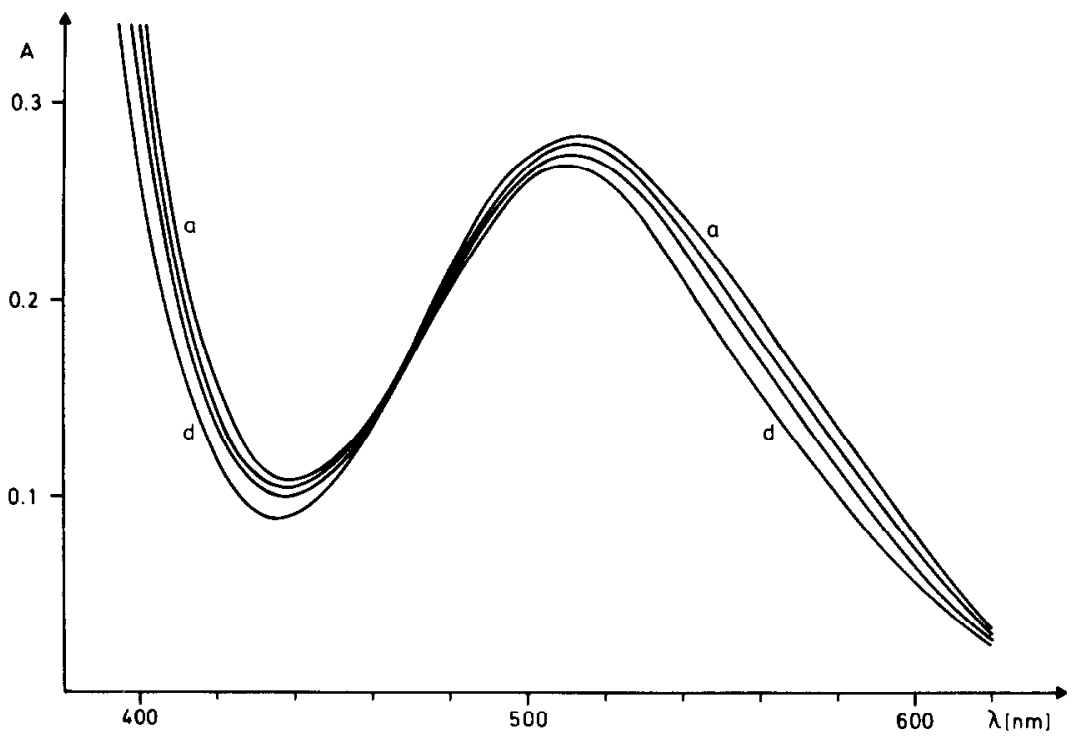

Figure 2. Spectral changes during the photolysis of $3.8 \times 10^{-3} M \mathrm{Co}\left(\mathrm{NH}_{3}\right)_{5} \mathrm{SCN}^{2+}$ in $10^{-2} M \mathrm{HClO}_{4} ; 333 \mathrm{~nm}$ irradiating wavelength. Reading downward: $0 \mathrm{~min}(\mathrm{a}), 15 \mathrm{~min}, 30 \mathrm{~min}, 60 \mathrm{~min}$ (d) irradiation time.

place is certainly justified. However, the accuracy of the measurements is not great enough to exclude the formation of very small amounts of other photoproducts as for example $\mathrm{Co}\left(\mathrm{NH}_{3}\right)_{5} \mathrm{H}_{2} \mathrm{O}^{3+}$. If secondary photolysis of $\mathrm{Co}\left(\mathrm{NH}_{3}\right)_{5} \mathrm{NCS}^{2+}$ was avoided the change of the optical density at any wavelength was not large due to the high extinction of $\mathrm{Co}\left(\mathrm{NH}_{3}\right)_{5} \mathrm{NCS}^{2+}$. The photolysis foilowed a zeroth order kinetics up to $7 \%$ of photolyzed starting complex.

Since the efficiency of the photoisomerization is independent of the concentration of $\mathrm{Co}\left(\mathrm{NH}_{3}\right)_{5} \mathrm{SCN}^{2+}$ the rearrangement should occur by an intramolecular mechanism. The photolysis produced also free $\mathrm{NCS}^{-}$ with the quantum yield $\Phi=0.33$. The formation of $\mathrm{NCS}^{-}$Inust then result from side reactions of the redox decomposition as it has been observed in similar cases. $^{8,15}$

\section{Photolysis in the Solid State}

Since the extinction of the CT bands of $\mathrm{Co}\left(\mathrm{NH}_{3}\right)_{5}$ $\mathrm{SCN}^{2+}$ and its linkage isomer is rather high any photoisomerization of pure $\left[\mathrm{Co}\left(\mathrm{NH}_{3}\right)_{5} \mathrm{SCN}\right] \mathrm{Cl}_{2}$ would be restricted to the surface of the crystals and hence difficult to detect. A dilution was achieved by incorporation of $\left[\mathrm{Co}\left(\mathrm{NH}_{3}\right)_{5} \mathrm{SCN}\right] \mathrm{Cl}_{2}$ in $\mathrm{KBr}$ pellets. These pellets are also useful for the detection of linkage isomerization hy i.r. spectroscopy.

Upon irradiation of the LF band of $\mathrm{Co}\left(\mathrm{NH}_{3}\right)_{5} \mathrm{SCN}^{2+}$ $(\lambda>480 \mathrm{~nm})$ the i.r. spectrum did not change. However, shorter-wavelength irradiation into the CT band initiated a linkage isomerization with formation of $\left[\mathrm{Co}\left(\mathrm{NH}_{3}\right)_{5} \mathrm{NCS}\right] \mathrm{Cl}_{2}$ as indicated by the change of the i.r. spectrum as has been observed previously. ${ }^{6}$ The first observation of this photoisomerization ${ }^{6}$ which stimulated the present investigation was possibly due to the exposure of the starting complex to the UV light of the light source in the i.r. spectrometer. The linkage isomerization was apparently the only photochemical reaction in the solid state. $\mathrm{Co}^{2+}$ was not detected in an aqueous solution of the irradiated $\mathrm{KBr}$ pellets.

\section{Discussion}

It was shown that aqueous $\mathrm{Co}\left(\mathrm{NH}_{3}\right)_{5} \mathrm{SCN}^{2+}$ underwent a photoredox decomposition which is accompanied by a linkage isomerization with formation of $\mathrm{Co}\left(\mathrm{NH}_{3}\right)_{5} \mathrm{NCS}^{2+}$. At $333 \mathrm{~nm}$ irradiating wavelength the quantum yields were $\Phi=0.48$ for redox reaction and $\Phi=0.24$ for isomerization. If solid $\left[\mathrm{Co}\left(\mathrm{NH}_{3}\right)_{5}\right.$ $\mathrm{SCN}] \mathrm{Cl}_{2}$ was irradiated only the linkage isomerization took place.

These photochemical reactions of $\mathrm{Co}\left(\mathrm{NH}_{3}\right)_{5} \mathrm{SCN}^{2+}$ are quite similar to those of $\mathrm{Co}\left(\mathrm{NH}_{3}\right)_{5} \mathrm{NO}_{2}{ }^{2+}$ which underwent a redox decomposition and a simultaneous linkage isomerization with formation of $\mathrm{Co}\left(\mathrm{NH}_{3}\right)_{5}$ $\mathrm{ONO}^{2+3-5}$ The photoisomerization also occured in the solid state. ${ }^{3}$ However, in contrast to $\mathrm{Co}\left(\mathrm{NH}_{3}\right)_{5}$ $\mathrm{NO}_{2}{ }^{2+}$ which was photosensitive over its entire absorption spectrum the photoreactivity of $\mathrm{Co}\left(\mathrm{NH}_{3}\right)_{5}$ $\mathrm{SCN}^{2+}$ was restricted to the CT region. Upon irradiation of the LF band no photochemical change was observed. Hence we conclude that the photochemical reactions of $\mathrm{Co}\left(\mathrm{NH}_{3}\right)_{5} \mathrm{SCN}^{2+}$ were initiated by an excited CT state. 
In analogy to $\mathrm{Co}\left(\mathrm{NH}_{3}\right)_{5} \mathrm{NO}_{2}{ }^{2+3-5}$ the photochemistry of $\mathrm{Co}\left(\mathrm{NH}_{3}\right)_{5} \mathrm{SCN}^{2+}$ may be explained on the basis of a radical pair model..$^{3-5,7,8,15}$ The separation of the radicals $\mathrm{Co}\left(\mathrm{NH}_{3}\right)_{5}{ }^{2+}$ and $\mathrm{NCS}$ which were produced in the primary step following $\mathrm{CT}$ excitation led to the redox reaction whereas the linkage isomerization should be the result of a primary or secondary geminate recombination of the radicals. In the solid state a separation of the radical pair is apparently not possible. Hence only the linkage isomerization was observed.

It is then interesting to compare the photochemistry of $\mathrm{Co}\left(\mathrm{NH}_{3}\right)_{5} \mathrm{SCN}^{2+}$ and its linkage isomer since CT excitation of hoth complexes should produce identical radicals. Earlier investigations have shown that $\mathrm{CT}$ excitation of aqueous $\mathrm{Co}\left(\mathrm{NH}_{3}\right)_{5} \mathrm{NCS}^{2+}$ led to a redox decomposition and an aquation with formation of $\mathrm{Co}\left(\mathrm{NH}_{3}\right)_{5} \mathrm{H}_{2} \mathrm{O}^{3+}{ }^{7,8}$ The relative efficiencies of the two reaction modes were $70 \%$ redox reaction and $30 \%$ aquation. ${ }^{8}$ Both reactions have been assumed to have also the radical pair $\mathrm{Co}\left(\mathrm{NH}_{3}\right)_{5}{ }^{2+}$ and $\mathrm{NCS}$ as a common precursor. The absence of any photoisomerization of $\mathrm{Co}\left(\mathrm{NH}_{3}\right)_{5} \mathrm{NCS}^{2+}$ may be an indication that the radical recombination led always to the isothiocyanato isomer. However, the observation that only one of the linkage isomers, $\mathrm{Co}\left(\mathrm{NH}_{3}\right)_{5} \mathrm{NCS}^{2+}$, undergoes an efficient photoaquation suggests that the reactivity of the radical pair generated in the first step is not independent of the way in which it is produced.

Any conclusive explanation of the different behavior of both isomers cannot yet be given. However, the occurrence of the photochemical linkage isomerization of the thiocyanato isomer may be releated to the observation that the $\mathrm{Co}-\mathrm{SCN}$ bond is bent at the sulfur atom with an angle of $105^{\circ}$ while the Co-NCS bond is linear. ${ }^{16}$ The radical pair formation following CT excitation should be associated with a motion of the coordinating ligand atom away from the metal center. In the case of the thiocyanato isomer this motion could lead to a rotation of the $\mathrm{SCN}$ radical. Its nitrogen atom may then move into a favorable position to reattach to the complex fragment. Alternatively, the different reactivity of both isomers may be used to support an excited state model. ${ }^{17}$ However, it is our opinion that in comparison to the radical pair model the excited state mechanism is based on much more arbitrary assumptions which are difficult to verify.

\section{Acknowledgement}

Support for this research by the Deutsche Forschungsgemeinschaft and the Fonds der Chemischen Industrie is gratefully acknowledged.

\section{References}

1 A.W. Adamson, W.L. Waltz, E. Zinato, D.W. Watts, P.D. Fleischauer and R.D. Lindholm, Chem. Rev., 68, 541 (1968).

2 V. Balzani and V. Carassiti, "Photochemistry of Coordination Compounds", Academic Press, New York, N.Y., 1970.

3 V. Balzani, R. Ballardini, N. Sabbatini and L. Moggi, Inorg. Chem., 7, 1398 (1968).

4 F. Scandola, C. Bartocci and M.A. Scandola, J. Am. Chem. Soc., 95, 7898 (1973).

5 F. Scandola, C. Bartocci and M. A. Scandola, J. Phys. Chem., 78, 572 (1974).

6 D. A. Buckingham, I. I. Creaser and A. M. Sargeson, Inorg. Chem., 9, 655 (1970).

7 a) A. W. Adamson and A.H. Sporer, J. Am. Chem. Soc., 80,3865 (1958).

b) A. W. Adamson and A. H. Sporer, J. Inorg. Nucl. Chem., $8,209(1958)$.

8 A.W. Adamson, Discuss. Faraday Soc., 29, 163 (1960).

9 J.F. Endicott and G.J. Ferraudi, J. Am. Chem. Soc., 96, 3681 (1974).

10 R. L. Carlin and J. O. Edwards, J. Inorg. Nucl. Chem., 6, 217 (1958).

11 C. G. Hatchard and C. A. Parker, Proc. Roy. Soc., Ser. A, 235, 518 (1956).

12 E.E. Wegner and A.W. Adamson, J. Am. Chem. Soc, 88,394 (1966).

13 R.F. Kitson, Anal. Chem., 22, 664 (1950).

14 D.F. Gutterman and H. B. Gray, J. Am. Chem. Soc., 93, 3364 (1971).

15 A. Vogler and A.W. Adamson, J. Phys. Chem., 74, 67 (1970).

16 M. R. Snow and R. Boomsma, Acta Crystallogr., B 28, 1908 (1972).

17 see Ref. 9 and references cited therein. 